\title{
Bardet-biedl syndrome: A case report from Nepal
}

\author{
Rajesh Kumar Mandal', Rajan Pande ${ }^{2}$, Rajani Shah KC ${ }^{3}$, Bibek Acharya ${ }^{4}$ \\ ${ }^{1,3}$ Consultant Physician, ${ }^{2}$ Chief Consultant Physician, Department of Internal Medicine, Bheri Hospital, Nepalgunj, \\ Nepal, ${ }^{4}$ Consultant Ophthalmologist, Department of Ophthalmology, Bheri Hospital, Nepalgunj, Nepal
}

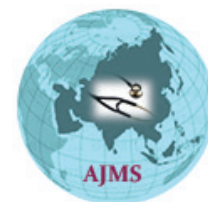

\section{A B S T R A C T}

The Bardet-Biedl syndrome (BBS) is a rare ciliopathic autosomal-recessive disorder, with multiple organ systems involved. It is usually seen in families with consanguineous marriage. It is characterized by truncal obesity, polydactyly, retinal dystrophy, mental retardation, renal dysfunction and hypogonadism in males. It affects both males and females. Very few cases are reported in Nepal. Here we report a 30-year obese lady who presented to our center with history of excessive weight gain and blindness with polydactyly. She visited many local medical centers before landing at our hospital.

\section{Access this article online}

Website:

http://nepjol.info/index.php/AJMS DOI: $10.3126 /$ ajms.v12i8.38262

E-ISSN: 2091-0576

P-ISSN: 2467-9100

Copyright (c) 2021 Asian Journal of Medical Sciences

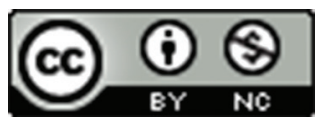

This work is licensed under a Creative Commons Attribution-NonCommercial 4.0 International License.

\section{INTRODUCTION}

The Bardet-Biedl syndrome (BBS) is a rare ciliopathic human autosomal-recessive disorder, which is characterized primarily by cardinal symptoms of marked truncal obesity, retinal dystrophy, polydactyly, mental retardation, hypogonadism and renal dysfunction. ${ }^{1}$ It was first described by Laurence and Moon in 1866 and additional cases were described by Bardet and Biedl between 1920 and 1922. ${ }^{2}$ There are 21 known BBS genes (BBS1-BBS20 and NPHP1) till date, out of which BBS1 and BBS10 are common genetic mutations. ${ }^{3}$ Molecular genetic testing is available for common mutations on clinical basis for BBS1 and BBS10. ${ }^{4}$ Its frequency in Europe and North America is 1:100,000. ${ }^{5}$ The disease incidence of this syndrome is higher in the Faroe Islands and Kuwait with 1:3700 and 1:17,000 live births respectively. ${ }^{6}$ India reported less than 15 cases. ${ }^{7}$ Exact report of Bardet Biedl syndrome in Nepal is not known.
Due to genetic heterogeneity diagnosis of BBS primarily depends upon the clinical findings and family history. Four primary features or three primary and two secondary features are diagnostic for BBS. ${ }^{1}$ The primary manifestations of BBS are rod-cone dystrophy (93\%), postaxial polydactyly (63-81\%), obesity (72-92\%), learning disabilities (61\%), genital abnormalities (59-98\%) and renal abnormalities both morphological and functional (53\%). Other secondary features are not always present include speech disorder or delay (54-81\%), hepatic fibrosis, diabetes mellitus (6$48 \%)$, mild spasticity specially in the lower limbs, spinal problem, brachydactyly (6-100\%), ataxia (40-86\%), facial dysmorphism (51\%), and developmental delay $(50-91 \%){ }^{8}$

BBS being a rare genetic disorder can be easily missed by primary care givers and specialists. Here, the authors present a classic case of BBS of a 30-year female who visited medicine out patient department with history 
of bilateral lower limb swelling, excessive weight gain and blindness with features of marked truncal obesity, polydactyly and mental retardation. This case report intends to sensitize physicians, pediatricians and ophthalmologist in this region toward this rare genetic disorder.

\section{CASE PRESENTATION}

A 30-year female was brought to the Medicine Out Patient Department with a history of bilateral lower limb swellings for 3 months and excessive weight gain for the last six months. She was escorted by her elder sister as she could hardly see anything. A detail history was asked from her birth and childhood. She was born to non-consanguineous parents. The birth was a normal vaginal delivery and was of normal weight. Her milestones were delayed. She had neck holding at 7 months, could sit without support at 16 months and could walk at 3 years and run at 4 years. She attained pincer grip at around 2 years and tried scribbling at the age of 4 years. Regarding her speech, she had monosyllable (ma, ba) at the age of 12 months, bi syllable (ma ma, ba ba) at 18 months and she could speak two to three words at the age of 3 years. She had decreased interaction with the family members since child hood. These features suggest that there was developmental delay during her childhood. She was admitted in school at the age of 5 years but due to her slowness and inability to grasp could not continue the study.

She had painless, gradual diminution of vision since childhood increasing in severity from 10-15 yrs. Previously the patient had decreased vision at night (night blindness since $15 \mathrm{yrs}$. of age) but recently she has reduced vision in day time also. At the time of history taking her visual acuity in both eyes were hand movement (with perception of light positive in all quadrants) and no improvement of vision with pinhole. Gradually the daytime vision also decreased and for the past 5 years she could barely see and became dependent on her caregivers for mobility. She had delayed menarche at the age of 20 years and had little flow and had irregular cycles. For the last 6 months she had amenorrhoea. Her weight kept on increasing since childhood. At the age of 10 her weight was around $50 \mathrm{~kg}$. The weight kept on increasing gradually. For the past 3 years it has increased to an extent that she has difficulty in climbing stairs. She also complained about her abdominal distention for six months. Initially it was gradual onset and was progressive in nature. For the last three months she also noticed bilateral lower limb swellings also. The swelling pitted on application of pressure and was relieved by diuretics given by local medical practitioners. However, the swelling re-occurred and she decided to visit our center which has been a tertiary care center in this region.
On examination her blood pressure was $130 / 80 \mathrm{~mm} \mathrm{Hg}$ and pulse was 84 beats per minute. Her weight was $90 \mathrm{~kg}$, height $153.5 \mathrm{~cm}$ and Body Mass Index was $39.46 \mathrm{~kg} / \mathrm{m} 2$. Thus, she was extremely obese (Image 1a). Her waist circumference was $118 \mathrm{~cm}$, hip circumference was $127 \mathrm{~cm}$ and waist to hip ratio was 0.92 . Her abdominal girth was $138 \mathrm{~cm}$. The ratio between the height and the distance between the external occipital protuberance and the Cervical 7 spinous process was $13.95(153.5 \mathrm{~cm} / 11 \mathrm{~cm})$. This was $>13.6$, which indicates that the patient had a short neck according to Bird's index. Polydactyly was present in bilateral upper and lower limbs (Image 1b-1d) after birth however extra finger from right hand (Images 1e and 1f) was removed surgically during childhood.

On ophthalmic examination her visual acuity in both eyes were hand movement (with perception of light positive in all quadrants) and no improvement of vision with

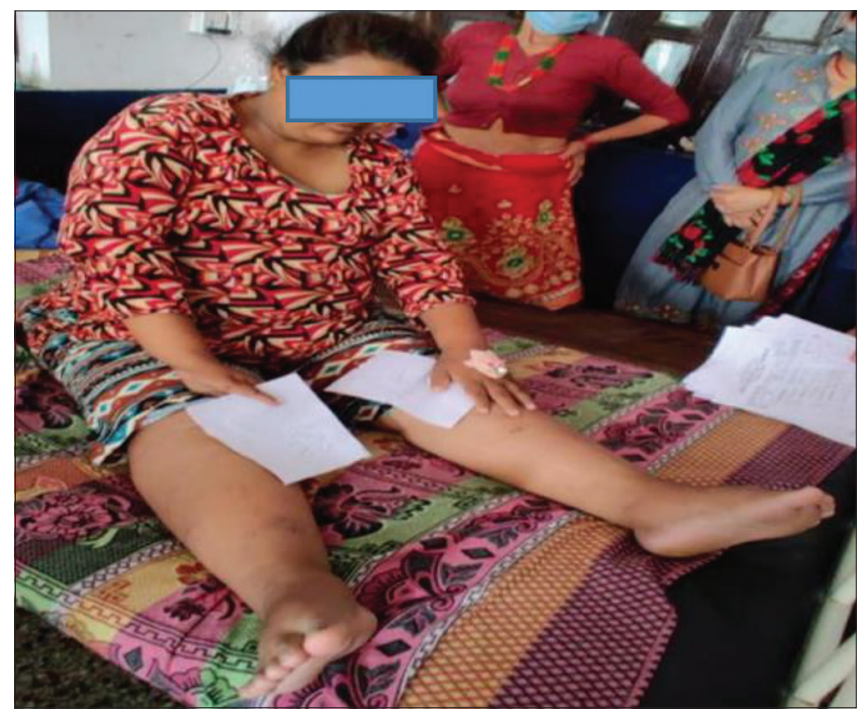

Image 1a: Obesity in the patient

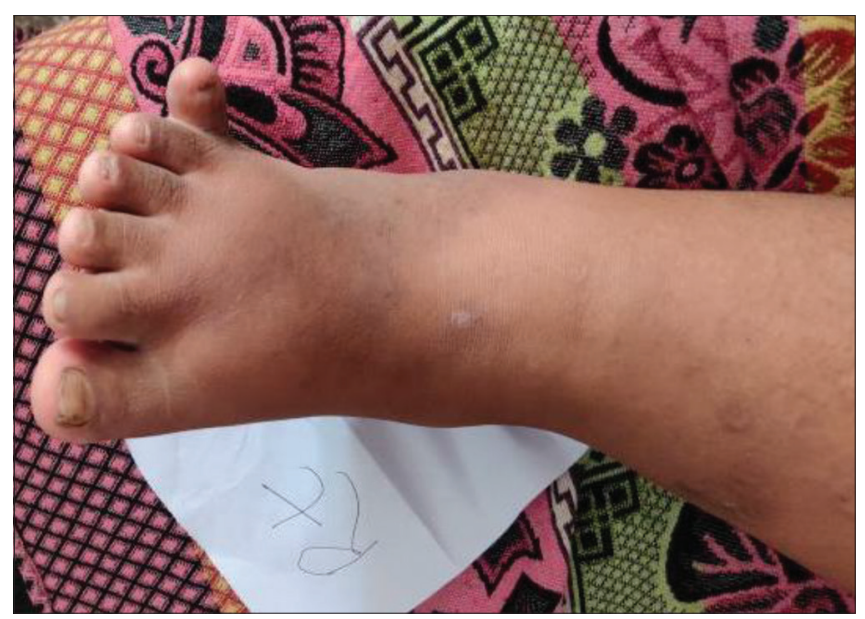

Image 1b: Polydactyly in Right foot 


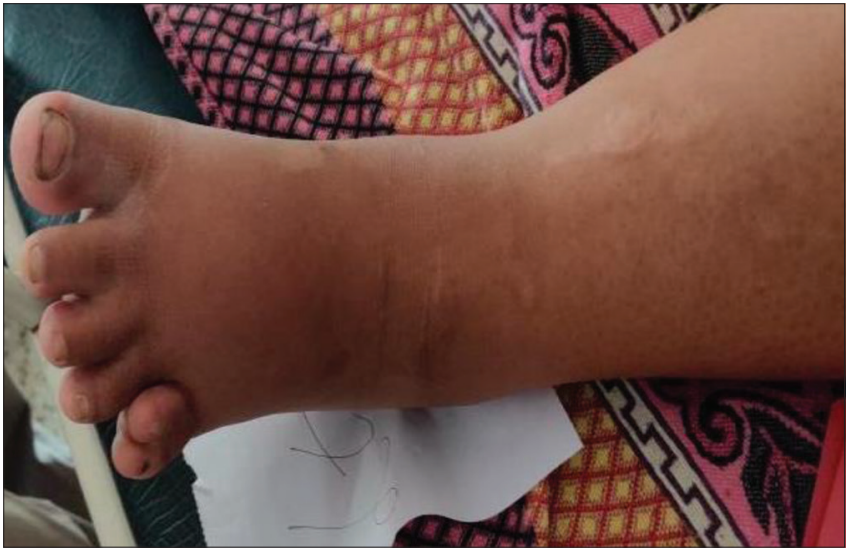

Image 1c: Polydactyly in Left foot

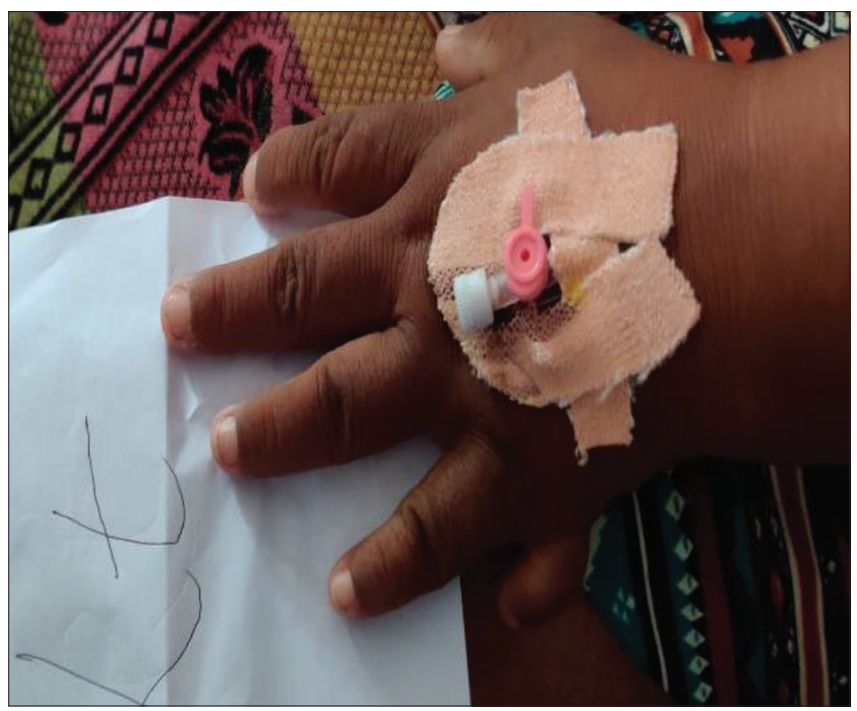

Image 1d: Polydactyly in Left hand

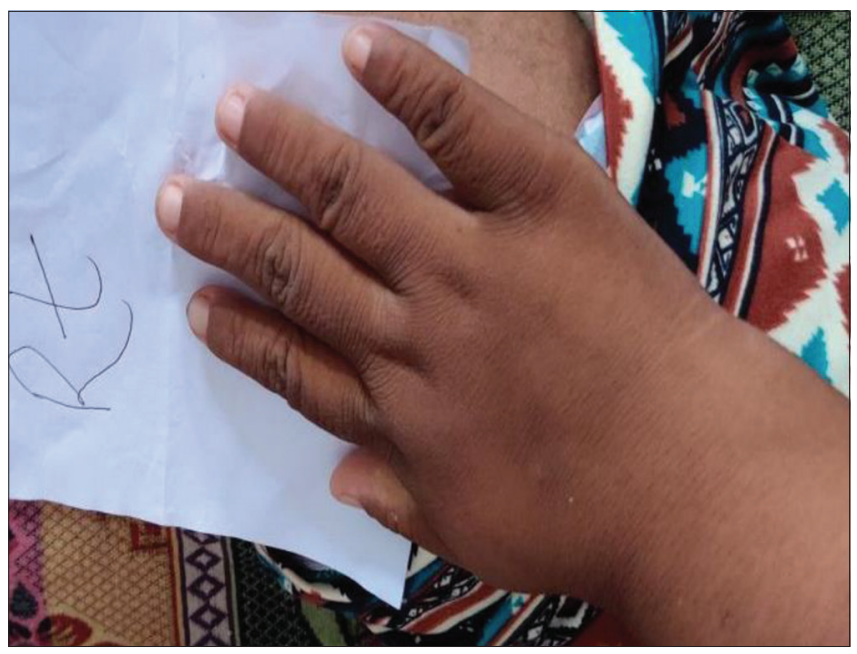

Image 1e: Remaining five fingers in Right hand

pinhole. Her Intraocular pressure was 12 in RE and 14 in LE measured with Goldmann Applanation tonometer on 2021/7/1.

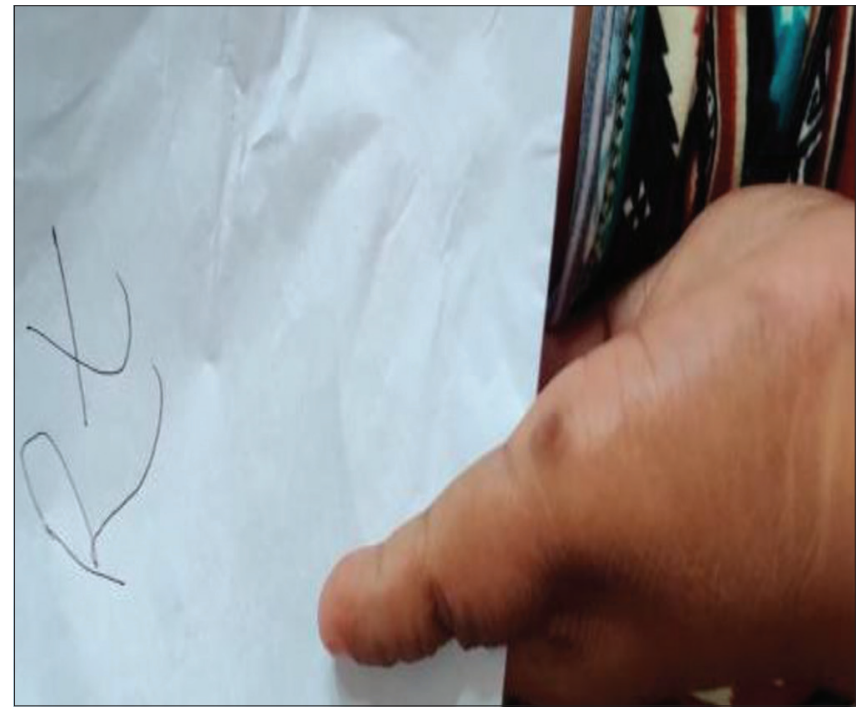

Image 1f: Scar of removed extra finger from Right hand

\section{ON SLIT LAMP EXAMINATION OF EYE ON (2021/7/1)}

OU (both eyes): Her eyelids were normal, with normal conjunctiva, Cornea was clear and transparent. The Anterior chamber angle was normal (van herick grade 4), Anterior chamber was quiet, with normal iris structure. There was Mild PSCC (posterior subcapsular cataract grade 1) in both eyes. The vitreous was clear.

\section{ON DILATED FUNDUS EXAMINATION USING TROPICAMIDE $1 \%$}

On dilated fundus examination of both eyes using 90 Diopter lens in slit lamp, the optic disc was pale suggestive of optic atrophy with degenerative lesions with atrophic patches in all quadrants (aka bony spicules-characteristic of Retinitis pigmentosa). There was macular atrophy in both eyes which could be the cause of reduced vision. Images 2 and 3.

Four primary features are required or three primary plus two secondary features are required for clinical diagnosis of BBS. In this case four primary and four secondary features were present, thus the diagnosis of BBS is established.

Ultrasonography of Abdomen and pelvis revealed that there was increased echogenicity and irregular outline of liver parenchyma with free fluid in the peritoneal cavity suggestive of gross ascites and liver cirrhosis. Cirrhosis of the liver refers to the advanced stage of liver fibrosis. Her both kidneys were normal in size (Right Kidney $10 \mathrm{~cm}$, Left Kidney $11 \mathrm{~cm}$ ), outline and echo texture. The Cortico medullary differentiation was maintained and there 


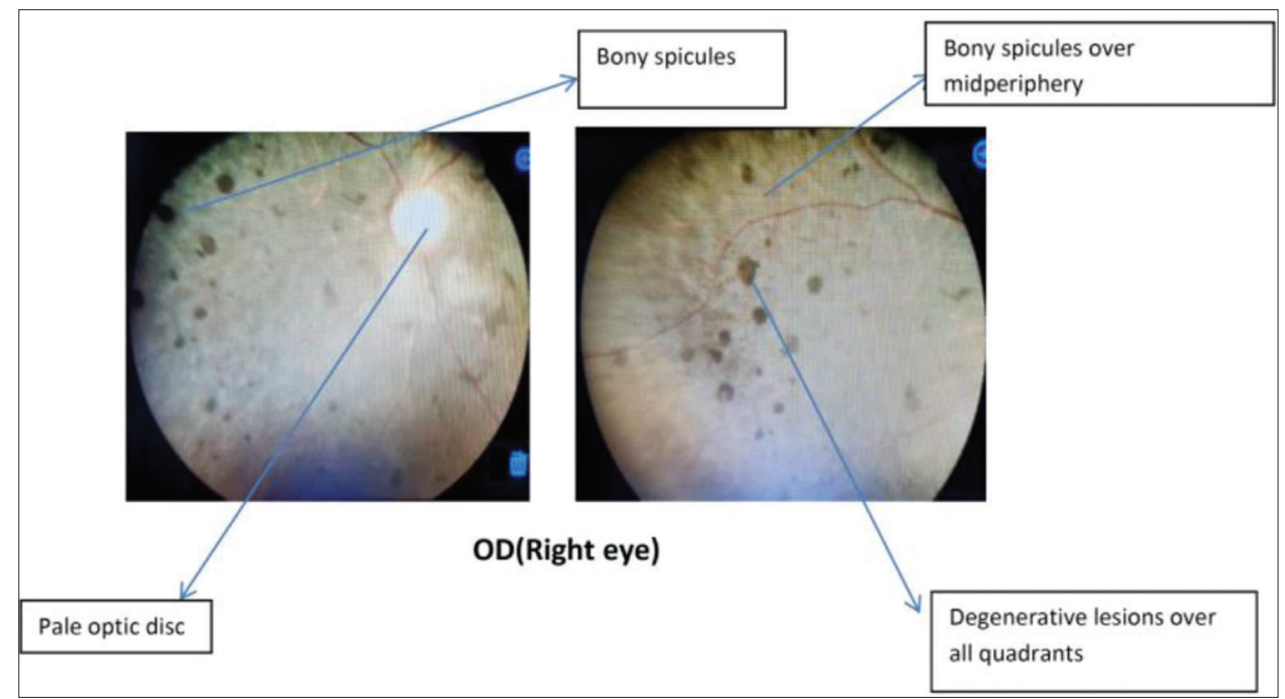

Image 2: Fundus Examination of Right Eye

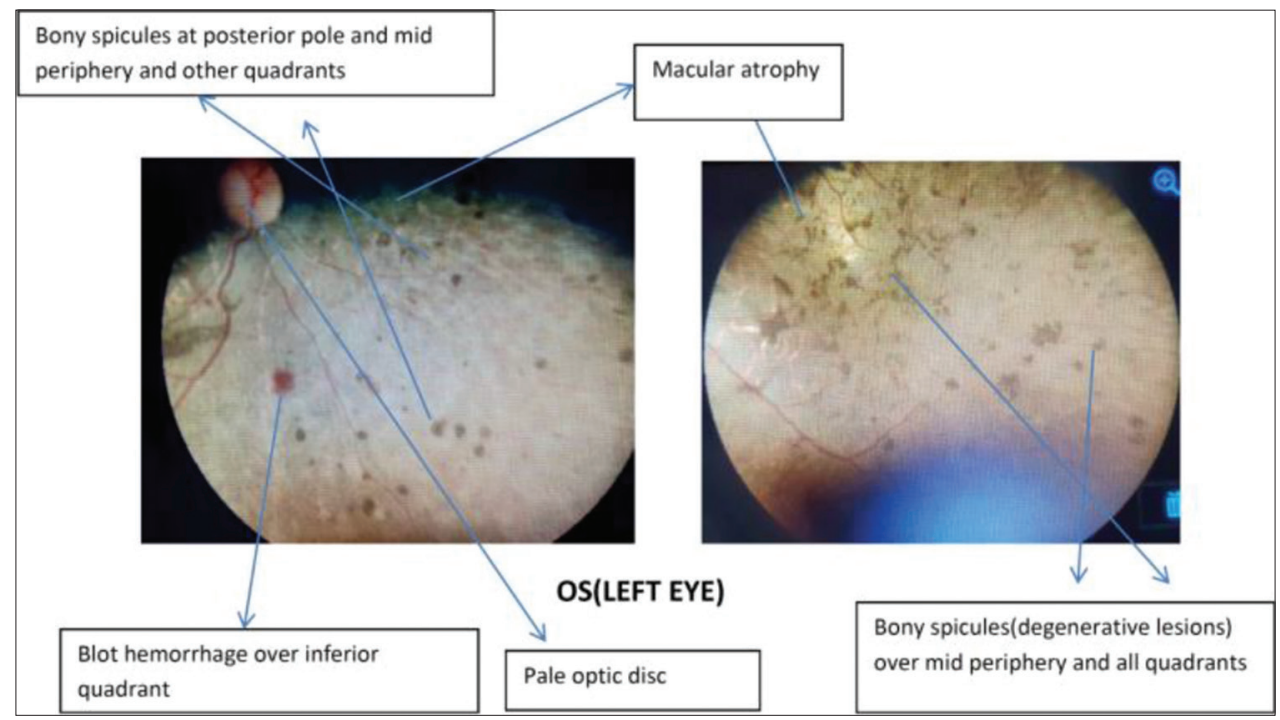

Image 3: Fundus Examination of Left eye

were no structural anomalies. Her blood investigations like haemogram, renal function tests, liver function tests, thyroid function tests and urine microscopy were normal. Her fasting plasma glucose was impaired with $118 \mathrm{mg} / \mathrm{dl}$. Her serum albumin was $2.9 \mathrm{mg} / \mathrm{dl}$ which was low suggestive of hypoalbuminemia. Her serology for Hepatitis B, Hepatitis C and HIV was non-reactive. Her Electrocardiogram and chest $\mathrm{X}$ ray were normal.

\section{DISCUSSION}

Bardet-Biedl syndrome (BBS) is a rare autosomal recessive disorder with clinical and genetic heterogeneity. Laurence-Moon-Biedl-Bardet syndrome (LMBBS) is not considered as a right term now. Laurence and Moon had paraplegia but no polydactyly and obesity. However, polydactyly and obesity are primary features of BBS. Thus, Laurence-Moon syndrome is considered to be a separate entity. ' Till date there are twenty-one known BBS genes (BBS1-BBS20 and NPHP1). These gene numbers are expected to rise owing to the invention of exome sequencing and analysis of previously unstudied populations. Among them, BBS1 and BBS10 are the two main genes involved in BBS and each of this gene mutation is present in more than $20 \%$ of the cases. ${ }^{3}$ The BBS proteins are components of the centrosome and affect the ciliary transport; hence, the disease falls under the spectrum of "ciliopathies."

In Table 1, The primary and secondary features of BBS have been described. For BBS the diagnostic criteria are 


\begin{tabular}{lc} 
Table 1: The Diagnostic criteria of Bardet-Biedl \\
Syndrome ${ }^{1}$ \\
\hline Primary features & Our Case \\
\hline Rod-cone dystrophy (93\%) & + \\
Polydactyly (63-81\%) & + \\
Obesity (72-92\%) & + \\
Learning disabilities (61\%) & + \\
Genital anomalies (59-98\%) & - \\
Renal anomalies (53\%) & - \\
\hline Secondary features & + \\
\hline Speech disorder/delay (54-81\%) & + \\
Strabismus/cataracts/astigmatism & - \\
Brachydactyly/syndactyly (6-100\%)/(8-95\%) & + \\
Developmental delay (50-91\%) & - \\
Ataxia/poor coordination/imbalance (40-86\%) & - \\
Spinal problem & - \\
Mild spasticity (especially lower limbs) & - \\
Diabetes mellitus (6-48\%) & - \\
Dental crowding/ hypodontia/small roots/high & \\
arched palate (51\%) & - \\
Left ventricular hypertrophy/congenital heart & \\
disease (51\%) & + \\
Hepatic fibrosis & - \\
Anosmia (60\%) & \\
\hline
\end{tabular}

either four primary features or three primary and two secondary features. Four primary and four secondary features have been observed in our patient thus fulfilling the diagnostic criteria of BBS. One of the cardinal clinical features of this rare genetic disorder is visual impairment in the form of Retinitis Pigmentosa. Visual impairment is present in almost all patients in the second decade to third decade (as in our case) of life however its presentation in the first decade of life is not uncommon. Macular involvement leads to decreased visual acuity, night blindness and even totally blind. Obesity is the second most important feature in BBS. Obesity begins in the childhood period, noticed at around 10 years of age usually by parents. As age increases BMI also increases. ${ }^{1}$ various renal abnormalities like parenchymal cysts, calyceal clubbing, fetal lobulation, scarring, unilateral agenesis, dysplastic kidneys, renal calculi, and vesico-ureteric reflux, chronic renal failure are seen in patients of BBS. But our patient had no renal abnormalities. Renal failure is the major cause of morbidity and early mortality in BBS and $25 \%$ die by the age of 44 year. $^{3}$

Early diagnosis of the case is the mainstay of management. Multidisciplinary approach is required in Bardet-Biedl syndrome. Early childhood obesity should be addressed by a balanced diet and physical training and exercise. Vision is a prime concern, the patients with BBS should have regular ophthalmologist consultation and examination. Refractive error if present should be corrected. Low vision aids can be tried for the visually impaired. Nonfunctional digits can be removed surgically for cosmetic reasons. Genitourinary and congenital cardiac abnormalities can also be managed surgically. Genetic counselling should be done among the patient's family members by Genetic experts or health professionals.

\section{CONCLUSIONS}

Bardet-Biedl Syndrome is a rare genetic disease of multiple organ system involvement. Pediatricians, physicians and ophthalmologists should have enough knowledge about this disease so that it can be diagnosed in early childhood. It can be missed due to its scarcity as in our case. Early diagnosis and multi-disciplinary management can improve morbidity and living standard in the affected individual.

\section{ACKNOWLEDGEMENT}

We would like to acknowledge Dr. Rajeshi Shrestha, Consultant Ophthalmologist, Fateh Bal Eye Hospital and Dr. Bishnu Kumar Thapa, Consultant Pediatrician, Bheri Hospital for their support, without which this case report would not have been possible.

\section{REFERENCES}

1. Beales PL, Elcioglu N, Woolf AS, Parker D and Flinter FA. New criteria for improved diagnosis of Bardet-Biedl syndrome: Results of a population survey. J Med Genet. 1999; 36: 437-446.

2. Jones KL. Bardet-Biedl syndrome: Smith's Recognizable Patterns of Human Malformation $5^{\text {th }}$ edition, Saunders company; 1997. p.590-591.

3. Begum S, Benzamin Md, Karim MR and Mazumdar AB. BardetBiedl Syndrome- A Case Report. Sch J App Med Sci. 2018; 6(7): 2898-2901.

4. Nachury MV, Loktev AV, Zhang Q, Westlake CJ, Peranan J, Merdes A, et al. A core complex of BBS proteins cooperates with the GTPase Rab8 to promote ciliary membrane biogenesis. Cell. 2007; 129:1201-1213.

https://doi.org/10.1016/j.cell.2007.03.053

5. Forsythe $\mathrm{E}$ and Beales PL. Bardet-Biedl syndrome. European Journal of Human Genetics. 2013;21(1):8. https://doi. org/10.1038/ejhg.2012.115

6. Hjortshøj TD, Grønskov K, Brøndum-Nielsen $\mathrm{K}$ and Rosenberg T. A novel founder BBS1 mutation explains a unique high prevalence of Bardet-Biedl syndrome in the Faroe Islands. British Journal of Ophthalmology. 2008.

https://doi.org/10.1136/bjo.2007.131110

7. Hooda AK, Karan SC, Bishnoi JS, Nandwani A and Sinha T. Renal transplant in a child with Bardet Biedl syndrome: A rare cause of end-stage renal disease. Indian J Nephrol. 2009; 19:112-114. 
https://doi.org/10.4103/0971-4065.57108

8. Saber S, Hossain M, Alam M, Hossain M and Gulzar S. Bardet Biedl Syndrome: A Rare Case Report in a Tertiary Care Teaching Hospital, Dhaka, Bangladesh. 2021.

https://doi.org/10.24018/ejmed.2021.3.1.623
9. Moore SJ, Green JS, Fan Y, Bhogal AK, Dicks E, Fernandez BA, et al. Clinical and genetic epidemiology of Bardet-Biedl syndrome in Newfoundland: A 22-year prospective, population-based, cohort study. Am J Med Genet. 2005; 132:352-356.

https://doi.org/10.1002/ajmg.a.30406

Author's Contribution:

RKM - Concept and design, Literature review, manuscript preparation, Critical review of manuscript and treating physician; RP - Concept and design, Critical review of manuscript and treating physician; RSKC - Literature review, manuscript preparation and treating physician; BA - Literature review, manuscript preparation and treating Ophthalmologist

\section{Work Attributed to:}

Department of Internal Medicine, Bheri Hospital, Nepalgunj, Nepal.

Orcid ID:

Dr. Rajesh Kumar Mandal - (i) https://orcid.org/0000-0002-3099-3731

Dr. Rajan Pande - (i) https://orcid.org/0000-0001-9328-5145

Dr. Rajani Shah KC - (1) https://orcid.org/0000-0002-8228-6609

Dr. Bibek Acharya - (io https://orcid.org/0000-0001-8438-6227

Source of Funding: None, Conflict of Interest: None. 